\title{
Material Becoming
}

\section{Michele WiLlson \\ CURTIN UNIVERSITY}

\author{
Dianna Coole and Samantha Frost (eds) \\ New Materialisms: Ontology, Agency, and Politics \\ Duke University Press, Durham and London, 2010 \\ ISBN: 9780822347538 \\ RRP: US\$24.95 \\ William E. Connolly \\ A World of Becoming \\ Duke University Press, Durham and London, 2011 \\ ISBN: 9780822348795
}

RRP: US\$22.95

The field of internet studies, within which I work, investigates how we live with and through our technologies. Questions about how to situate, ethically and ontologically, the intersection of human bodies, biotechnology and communication technologies (software, hardware, algorithms and code) are an increasingly central 
concern. It seems insufficient to distance the human from the technical or at the very least to not accord seemingly autonomous functionings of code and algorithms, bots and so forth, with some kind of agentic capacity. Thus in internet, new media and media studies more generally, there is a growing interest in questions of materiality, rethinking how we might understand agency and how we think of matter, technologies, bodies and processes and the relationships or spaces between them.

While A World of Becoming by William E. Connolly and the collection, New Materialisms, edited by Dianne Coole and Samantha Frost are not directly concerned with the issues of technology, both books uncover, revitalise and rethink particular historical understandings and theories that recognise the intersection, imbrications and interplay of material-organic and inorganic-bodies and of processes. I will discuss each in part below and then recount some general observations across both books.

New Materialisms opens with an excellent overview of the impetus for, and the current state of play within, new materialism studies. Coole and Frost suggest the impetus for this renewed interest in materialism is prompted partly in reaction to the so-called cultural turn and also as an attempt to introduce some creative and positive responses to the world. This is a world in which biotechnologies, global warming and climate changes, transnational migration of people and information, and the potentialities of science, information and communication technologies require us to consider the relationship between humans, and other living and nonliving matter. These developments also call on us to rethink the categories of life, human, bodies, time and space.

Fundamentally, the new materialist approaches reject the understanding of human as a distinct, separate and privileged focus of study that interacts with dead or less capable matter (organic and inorganic). Indeed, the editors suggest, the new materialists argue for a posthuman, post-Cartesian positioning that would reject the understanding of humans as distinct from objects and instead insist on 'describing active processes of materialization of which embodied humans are an integral part, rather than the monotonous repetitions of dead matter from which human subjects are apart'. (8) As against seeing matter as inert, distinct and lacking agency, Coole in her later chapter on Merleau-Ponty asks, 'Yet is it not possible to imagine matter quite differently: as perhaps a lively materiality that is self-transformative and 
already saturated with the agentic capacities and existential significance that are typically located in a separate, ideal, and subjectivist, realm'? (92)

The editors' positioning of the various chapters in this book and, indeed, new materialist studies itself is rather celebratory-they argue that the new materialists are not negative and critical but rather affirming and constructive with an 'antipathy towards oppositional ways of thinking'. (8) This can be seen, for example, in the chapter by Elizabeth Grosz who advocates an understanding of freedom as capacity for action and calls for an 'open ontology of possibility'; or Pheng Cheah's explication of a non-dialectical, positive, materialism. A more positive and constructive approach is welcomed and indeed necessary if we are to overcome the impasse that seems to permeate left and right politics and their restricted offering of alternative visions of the future. However, this claim seems somewhat limited inasmuch as all the authors in this collection are revisiting, revising and reclaiming work by earlier (mostly dead) theorists going back even to Hobbes. Such a step is important; academia relies on building conversations and languages from previous work among a community of scholars, but I would have liked to have seen a little more 'looking forward' undertaken-perhaps a task for the new materialists from hereon.

Some of the chapters refashion understandings of phenomenology. Others position themselves against a Marxist notion of historical materialism, noting the importance of considering the economy and its materiality but also distancing themselves to various degrees from this approach. As with any critical theory orientation, there is concern about the disadvantaged, the disempowered and the marginalised. Indeed, as the editors note, 'what we have found so striking is that each essay is both profoundly philosophical and also inherently politically engaged'. (37) The range of topics, concerns and approaches taken are impressive. Time, agency, pain, fear, the autonomy of the subject, affect, surveillance, media, life and death are all taken up as matters for consideration, among many others.

The book is divided into three parts or themes: The Force of Materiality (an ontological reorientation that 'conceives of matter itself as lively or as exhibiting agency' (7)); Political Matters (biopolitics and bioethics, 'issues concerning the status of life and of the human' (7)) and Economies of Disruption (critical political economy 'where the nature of, and relationship between, the material details of everyday life and broader geopolitical and socioeconomic structures is being 
explored afresh' (7)). As the editors note, this is in some ways an arbitrary division given that many of the chapters could fall within more than one theme.

Part One: The Force of Materiality, has chapters by Jane Bennett, Pheng Cheah, Dianne Coole and Melissa A. Orlie. Bennett's 'A Vitalist Stopover on the Way to a New Materialism' argues that our current ways of privileging man as central, and important, works to justify and enable violence, inequity and injustice. Through her exposition of the work of Hans Driesch (whom she refers to as a critical vitalist) and Henri Bergson, Bennett opens up the notion of a vital materialism that is able to accommodate, indeed more than that, necessarily incorporates, the agentic capacities of living and non-living matter and recognises their role in the animation of matter and the arrangement of bodies. Cheah's 'Non-Dialectical Materialism' discusses and compares the work of Deleuze and Derrida to present a more positive and non-dialectical approach to considerations of materialism and ontology (than that posited by Marx and his followers). This a lucidly written but very abstract philosophical chapter that I found hard to follow at times. The relative abstraction of the discussion is noted by Cheah when he asks himself (and the reader) how this can be translated into a field of political enquiry or agenda. His response is to redirect with 'perhaps the better question to ask ... how they radically put into question the fundamental categories of political theory including the concept of the political itself'. (89) Coole's 'The Inertia of Matter and the Generativity of Flesh' draws on the work of Merleau-Ponty and particularly his Nature lectures of 1956 to 1960, to uncover what she suggest is his pursuit of a new ontology. She productively employs Merleau-Ponty's notion of folded reversible flesh, (96) as a way of thinking through an ontology of vital matter. Orlie's 'Impersonal Matter' finishes the section with a discussion of the work of Nietzsche to respond to critiques of materialist subjectivity that have difficulties accounting for creative human action, suggesting that his understanding of impersonal materialism provides the answer. These chapters provide a strong starting point for the book opening up some key issues and in particular understandings of matter, bodies and ontologies.

Part Two: Political Matters turns to more direct issues of political agency and the autonomy of the subject in relation to matter. Chapters by Elizabeth Grosz, Samantha Frost, William E. Connolly and Rosi Braidotti address the positioning of the theoretical and philosophical (human) subject and affirm a positive and 
generative politics. Grosz's 'Feminism, Materialism, and Freedom', advocates for understanding freedom (within feminist accounts) as capacity for action rather than as a reaction or response to the status quo. This is to work within the parameters and visions the status quo has dictated whereas Grosz shifts the conversation sideways instead (using the work of Bergson as a springboard) to ask what sort of future we want and to open up discussion about these possibilities. Or, as she calls it, a more 'open ontology of possibility'. Frost's 'Fear and the Illusion of Autonomy' considers fear and autonomy of the subject in Hobbes, linking it with specific notions and practices of temporality and subject formation. Connolly's 'Materialities of Experience' seems in many ways a precursor to his book, also discussed in this review. In this chapter, Connolly productively positions Merleau-Ponty, Foucault and Deleuze together alongside insights drawn from neuroscience, to explore the materiality of perception. This focus on perception incorporates memory, anticipation, emotions, tactile sensations, bodies and experiences; Connolly proposes a positive politics of affirmation or welcoming of a belonging to this world. Braidotti's 'The Politics of "Life Itself" and New Ways of Dying' affirms the 'politics of "life itself" as a form of active ethical citizenship', (204) presenting 'life itself" as a relentlessly generative force that takes into account human and non-human (inhuman and posthuman) forces. This is an accessible, forthright and at times amusing piece of writing that works effectively as a closing chapter for this section and for the introduction of the next.

Part Three: Economies of Disruption deals more directly with the relationship between and understanding of human positioning among various matter/s. Rey Chow's 'The Elusive Material: What the Dog Doesn't Understand' draws attention to the importance of cultural literacies and of iteration and repetition in the creation and transmission of understanding. Sara Ahmed's 'Orientations Matter' combines historical materialism with a materialism of the body or physical corporeality to discuss the many ways in which an item (she uses an example of the table) can present according to the theoretical approaches employed (with gender and colour blindness revealed). Sonia Kruks' 'Simone de Beauvoir: Engaging Discrepant Materialisms' concentrates on the shifts between Beauvoir's works The Second Sex and Old Age to suggest that Beauvoir brings together a combination of understandings of materiality working both from the 'inside out' with 
phenomenology and the 'outside in' through analysis of macro-structures and seriality. (276) Jason Edwards' 'The Materialism of Historical Materialism' is the final chapter in the section, and the book. Perhaps fittingly, it engages globally with Marx's historical materialism, issues of the nation-state system and global inequities.

As should be apparent from the descriptions above, the book covers a wide range of approaches, writers, locations and politics. This is challenging in terms of the reader's degree of familiarity with the texts engaged with but also exciting in the conversations that are opened up with and across the texts. William E. Connolly's book, $A$ World of Becoming, is similarly challenging in the breadth of the discussion, the material drawn upon in terms of the cross-disciplinary nature of the material and issues discussed. The 'anchor' is provided by Connolly's working through of the notion of time as becoming, seeing multiple temporal zones existing, intersecting and unsettling one another.

Connolly states, 'My judgement is that no fully adequate conception of human agency is available today'. (22) Such a conception must recognise the intersection of multiple temporal fields, interactions with materiality, with emotions, sensory perceptions and be able to account for flux, ingenuity and stabilisations. This is an ambitious and, at times, almost overwhelming book that takes on areas such as neuroscience, philosophy, theology, humanism and liberalism in order to unseat the liberal notion of an autonomous human agent who thinks and acts rationally. Connolly believes this notion is inadequate and fails to explain the world as it is today where there is evidence of global warming, human injustices, ethnic and religious conflict, and confusion. He suggests 'the most pressing need of today is to negotiate deep, multi-dimensional pluralism within and across territorial regimes', (83) which he sees resulting in not only opportunity but also increased antagonisms. Connolly suggests taking insights from across disciplines and from across theorists and practices. He posits a world of becoming where, in the main, there are long periods of relative stability but also periods or instances of change, innovation, rebellion and resistance. The book is partly an attempt to understand these periods and human action within them.

The book is organised into a prelude and then two parts (of three chapters each) separated by an interlude, ending with a postlude. The Prelude sets the scene through the discussion of a film scene and then a personally remembered event to 
open up the idea of multiple temporal fields or zones and complex navigation through and across them; a theme recurrent through the book. The Interlude consists of a series of quotes on singularity, difference, time, space and nature. These are drawn from the writings of theorists considered on the previous pages such as Whitehead, Deleuze, James and Heraclitus, providing a succinct, temporally disjunctive encapsulation of the first part of the book. The Postlude is an evocative but somewhat ambiguous collection of thoughts. The rationale for the two parts is unclear. Connolly notes that the various chapters should be read as 'a set of essays that seek to infuse and augment each other'. (11)

Chapter 1, 'Complexity, Agency and Time', outlines Connolly's position on 'connectionism' and agency. This includes engagement with the work of theorists, Alfred North Whitehead, Gilles Deleuze, William James, Stuart Kauffman, Ilya Prigogine and Friedrich Nietzsche (many of the same names as in the collection previously discussed). In Chapter 2, 'The Vicissitudes of Experience', Connolly discusses (as he did in his chapter in the previous text) Merleau-Ponty, Foucault, Delueze, neuroscience and the complexity of perception. However, Connolly here also notes an accelerating minoritisation of the world whereby there is exposure, within the same territories, of different minorities who must deal with the contradictions, rejections or the alternatives of each other. This constant jostling of difference positions faith as potentially optional. The chapter therefore examines Charles Taylor and Gilles Deleuze, suggesting that both think these problems are existential and more belief is needed. This leads Connolly to ask the question of 'how to restore belief in this world?' (62)

Chapter 3, 'Belief, Spirituality, and Time', proposes an ethic of cultivation: 'presumptive care for the diversity of life and the fecundity of the earth'. (79) It considers understandings of will and presents Connolly's own predisposition to understand will as possessing two dimensions: imbued tendencies to action and limited capacity to veto or redirect.

The second part of the book could be loosely said to engage more specifically and actively with the here and now. Chapter 4, 'The Human Predicament', explores the challenges raised by invoking a notion of becoming that undermines or questions humanism, monotheism and science. Connolly proposes four 'steps' to deal with the pluralisation of world in positive ways. 
Chapter 5, 'Capital Flows, Sovereign Decisions and World Resonance Machines' talks about abstract machines and boundary crossings. Connolly sees a growth or increase in spreading antagonisms and resentment that are a result in part of the growing minoritisation and pluralisation of the world. This chapter is partly a call to arms (theoretically at least though Connolly also wants to stress the importance of practice and the ways in which our everyday actions make a difference). The task, he writes, is to 'inhabit several roles in more militant, visible, creative, and improvisational ways, as we come to terms with their cumulative effects on the world'. (144)

Chapter 6, 'The Theorist and The Seer', starts with the question: 'If we live in a world of becoming [which has a particular understanding of time], what difference does that make to the vocation of political theory?' (148) In this chapter, Connolly expands on his idea of time as becoming, noting three assumptions:

First, the existence of multiple zones of becoming, each of which has at least some degree of openness; second, periodic encounters, not always predictable, between processes set on one tier of chrono-time and those on others, creating mergers, collisions, or potential for new vectors of development ; third, an uncertain degree of pluri-potentiality inhabiting several such temporal tiers, so that a new encounter between two or more could trigger a new capacity of self-organization in one, propelling it in directions that could exceed the its previous mode of organization, and a simple combination of them. (151-2)

A World of Becoming is a magnificent undertaking, which demands a lot from the reader in turn. Like New Materialisms it delves into the work of theorists past and present. However, it is also concerned with the positive and negative of the world today and engages with this to present some way forward. Like all ambitious undertakings, there are some difficulties, some tensions within. These do not detract significantly from the undertaking itself.

Two things are overwhelmingly obvious across both books: the approaches are diverse, messy and cross-disciplinary (although reworked phenomenology figures prominently) and both convey an underlying concern with politics and ethics across categories. The authors call on us to rethink the concepts of bodies, space, time, nature, objects and life itself in ways that encourage recognition of relationships 
between them, of overlaps, interconnections and non-linearity. Agency, change and creativity are brought under the spotlight and interrogated from many angles. This involves not only understanding the world we live in now and the ways change takes place and can be understood, but also a political imperative whereby ways of living together that allow for the voices and actions of all living-and indeed even nonliving-organic and inorganic matter is suggested. This is not an approach that sits comfortably with other work that considers material relations such as Actor Network Theory.

Taken together alongside recent books such as Packer and Crofts Wiley's Communication Matters: Materialist Approaches to Media, Mobility and Networks, these books offer a broad, insightful and at times innovative overview of the state of materialist thinking and theories of becoming, providing a useful palette of approaches to choose from. ${ }^{1}$ You will not come away from these books with a clear manifesto for the way forward or indeed even a relatively coherent encapsulation of what a (new) materialism or theory of becoming should look like. But you will have a broad spectrum of approaches and ideas from which to start.

Michele Willson is an associate professor in Internet Studies, Curtin University, Western Australia. She is interested in conceptualising sociality with and through our machines, and understanding how online constructs and architecture can be accommodated within such conceptualisations.

\section{-NOTES}

1 Jeremy Packer and Stephen B. Crofts Wiley, Communication Matters: Materialist Approaches to Media, Mobility and Networks, Routledge, Oxford, 2012. 